\title{
THE IDENTIFICATION AND CHARACTERISATION OF SOME PORCINE ARGININE-UTILISING MYCOPLASMA STRAINS
}

\author{
M. GoIŠ* AND D. TAYLOR-ROBINSON \\ Royal Veterinary College, Royal College Street, London, and M.R.C. Clinical \\ Research Centre, Watford Road, Harrow, Middlesex
}

Mycoplasmas that have been isolated from pigs can, at present, be placed in seven serologically distinct groups (Switzer, 1964; Dinter, Danielsson and Bakos, 1965; Goodwin, Pomeroy and Whittlestone, 1967; Taylor-Robinson and Dinter, 1968). Most of these mycoplasmas metabolise glucose. However, a few metabolise arginine and belong to the species Mycoplasma gallinarum and $M$. iners, which are otherwise found most frequently in birds. During recent examination of nasal cavities and pneumonic lesions of pigs, strains were isolated that utilised arginine and did not ferment glucose. Three of the strains were isolated in three different localities in England and were found to be serologically closely related, as briefly reported by Roberts and Goiš (1970). Furthermore, on the basis of metabolism-inhibition and disc growth-inhibition tests, the strains appeared to be distinct from the serotypes already known to occur in pigs. Therefore, these arginine-utilising strains were tentatively suggested as an additional mycoplasma species of pigs. Recently, Ross and Karmon (1970) have described arginine-utilising strains in pigs that they regard as a new species, $M$. hyosynoviae, and Friis (1970) has termed arginine-splitting strains that he isolated $M$. suidaniae.

This report presents biological data on our arginine-utilising strains, including their serological relationships with other members of the order Mycoplasmatales and with the recently designated porcine species.

\section{MATERIALS AND METHODS}

Mycoplasma strains. The mycoplasmas used, many for comparative purposes, are indicated in tables I and II.

Media. The initial isolation of the porcine mycoplasmas was in the liquid medium described by Goodwin, Pomeroy and Whittlestone $(1965,1967)$; this we refer to as medium B. For the propagation of mycoplasma isolates, for the growth of prototype strains and for metabolism-inhibition tests, the following liquid medium (referred to as A1) was used: Difco PPLO broth supplemented with 20 per cent. (v/v) Hartley digest broth, 20 per cent. ( $\mathrm{v} / \mathrm{v}$ ) unheated horse serum (from the Department of Medicine of the Royal Veterinary College Field Station or from Burroughs Wellcome: no. 6), 15 per cent. (v/v) yeast extract (some prepared according to Herderscheê, 1963), 0.002 per cent. (w/v) phenol red, 0.05 per cent. (w/v) thallium acetate, and 1000 Oxford units of penicillin $\mathrm{G}$ per ml. Antibiotics were omitted from some batches of medium. The medium was supplemented with either 0.25 per cent. (w/v) L-arginine hydrochloride or 0.1 per cent. (w/v) urea, or with 1.0 per cent. $(\mathrm{w} / \mathrm{v})$ glucose. The $p \mathrm{H}$ of the arginine-containing and urea-containing media was adjusted

Received 5 April 1971; accepted 8 June 1971.

* Present address: Veterinary Research Institute, Brno, Czechoslovakia.

J. MED. MICROBIOL.-VOL. 5 (1972) 
to $6 \cdot 9-7 \cdot 1$ and that of the glucose-containing medium to $7 \cdot 6-7 \cdot 8$. All cultures were incubated aerobically at $37^{\circ} \mathrm{C}$.

Solid medium for colonial growth consisted of medium A1 with 1.0 per cent. Difco Noble agar. Cultures on agar medium were incubated aerobically, or in air +5 per cent. $(v / v)$ carbon dioxide, or in nitrogen +5 per cent. ( $\mathrm{v} / \mathrm{v})$ carbon dioxide.

Collection of specimens. Samples were taken from a herd (Ha) that had an endemic respiratory infection. Nasal swabs were collected from 60 pigs at birth and at monthly intervals thereafter until they were killed for bacon or pork at 4-5 mth of age (55-80 kg weight). At this time, in addition to nasal specimens, parts of the lungs were removed. Nasal swabs were collected also from ten dams at the same intervals during the 5-mth period.

Isolation procedure. Cotton-wool swabs were pushed as far as possible into both nostrils and then immersed immediately in medium B. The lungs of pigs were ground and 10 per cent. suspensions were inoculated into medium B. Primary cultures were incubated for 8 days and during this time several subcultivations were made, usually at 48 -hr intervals. Subcultures were made at intervals of 3-5 days. After several passages in medium B, the mycoplasma strains were propagated in medium A1. All strains were then cloned by inoculating a single colony into liquid medium. This was incubated for 2-3 days before being subcultured on agar medium for colony development. The cloning procedure was repeated four times.

Titration of mycoplasmas. Quantitative estimations of mycoplasma organisms were done by making serial ten-fold dilutions in liquid medium containing phenol red indicator and either arginine or glucose. Growth of arginine-metabolising mycoplasmas was detected by a change in colour of the medium from yellow $(p \mathrm{H} \mathrm{7.0)}$ to pink $(p \mathrm{H} \geqslant 7.8)$ and the reverse change for glucose-metabolising strains. The highest dilution that produced a colour change after incubation at $37^{\circ} \mathrm{C}$ was the end-point of the titration and this was considered to contain one colour-changing unit (CCU).

Biochemical and other tests. All the mycoplasma strains were tested at $37^{\circ} \mathrm{C}$ in liquid medium A1, which contained phenol red as an indicator, for their ability to ferment 1.0 per cent. glucose with a decrease of medium $p \mathrm{H}$ and to hydrolyse 0.1 per cent. urea or 0.25 per cent. L-arginine with an increase of medium $p \mathrm{H}$. The tetrazolium-reduction test was performed by adding 0.01 per cent. (w/v) 2,3,5-triphenyl-tetrazolium chloride to the liquid medium; the culture media were incubated and observed for the development of a pink colour. Each strain was passed three times in the appropriate medium.

All recently isolated porcine strains were tested for their ability to grow in serum-deficient liquid medium. Subcultures to serum-deficient liquid medium were made three times at intervals of $48 \mathrm{hr}$. After incubation for $48 \mathrm{hr}$ the liquid media were subcultured to serumcontaining solid media, which were observed for the development of colonies. The same procedure was performed with liquid medium that contained horse serum.

Antiserum production. Antisera were prepared in rabbits by the injection of mycoplasmas concentrated 100 -fold by centrifugation. The antigen mixed with complete Freund's adjuvant was first given intramuscularly. Usually $3 \mathrm{wk}$ later the animals were given several intravenous injections at 3- or 4-day intervals. Sera were collected 4 days after the last inoculation, stored at $-20^{\circ} \mathrm{C}$ and heated at $56^{\circ} \mathrm{C}$ for $30 \mathrm{~min}$. before use. Some sera were obtained from Professor E. A. Freundt, University of Aarhus, Denmark, from Dr D. H. Roberts, Central Veterinary Laboratory, Weybridge, England, and from Dr R. F. Ross, Veterinary Medical Research Institute, Iowa State University, Ames, Iowa, USA.

Growth-inhibition (GI) tests. The filter-paper disk technique was that described by Clyde (1964). The disks were soaked with undiluted antiserum and the results were read after incubation in an aerobic or anaerobic atmosphere for $3-5$ days at $37^{\circ} \mathrm{C}$. Clear zones $1.5 \mathrm{~mm}$ or more in diameter were considered indicative of inhibition.

Metabolism-inhibition (MI) tests. These were done in Linbro Disposotrays (Flow Laboratories Ltd, Irving, Scotland). Studies with acid-producing mycoplasmas were carried out by the method of Taylor-Robinson et al. (1966), and those with arginine-metabolising mycoplasmas by a similar technique (Purcell et al., 1966). The procedure was modified slightly as follows: two drops $(0.05 \mathrm{ml})$ instead of one drop of antiserum dilution were used in each cup; 
in most tests the fluid in each cup was covered with one drop of liquid paraffin before the trays were sealed with "Sellotape". Guinea-pig serum was not used. Antibody titres were recorded when the $p \mathrm{H}$ of medium containing mycoplasmas without antiserum had changed

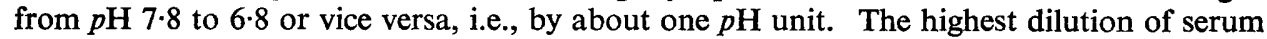
that prevented a $p \mathrm{H}$ change of at least half a unit was recorded as the antibody titre.

\section{RESULTS \\ Isolation of arginine-utilising (A-U) mycoplasma strains}

An A-U strain was isolated from the nasal cavities of three out of ten sows. Swabs taken from one sow on two successive occasions $1 \mathrm{mth}$ apart yielded A-U strains, one of which was labelled no. Ha1. Swabs from the other two sows yielded similar strains, no. Hal76 and Ha15; these were isolated only once from five specimens collected from each sow. Strain no. Ha15 was lost during the study and is not considered further.

Six A-U strains were isolated from the lungs of 60 pigs, 4-5 mth of age. $M$. hyorhinis also was isolated from many of the lung suspensions. Indeed, during the first 4 days of incubation of primary cultures in liquid medium B, $M$. hyorhinis only was recovered; on the 5th-8th days of incubation these organisms apparently died and then only the A-U strains were isolated. Thus, in this way A-U strains only were isolated from three lung specimens, and these organisms together with $M$. hyorhinis from three other lung specimens. Three or more different bacterial species were also isolated from the lungs that yielded mycoplasmas and in most of these lungs macroscopic lesions were present, the character of which is recorded in table I.

\section{Biological characteristics}

Colonies. On solid medium, each of the A-U mycoplasma strains produced typical " fried-egg" colonies, which developed to about $200 \mu \mathrm{m}$ diameter after 3 days' incubation in 95 per cent. $\mathrm{N}_{2}+5$ per cent $\mathrm{CO}_{2}$. Smaller colonies were noted after incubation in air +5 per cent. $\mathrm{CO}_{2}$ and even smaller colonies in an atmosphere of air only. Often a crystalline film developed on the agar surface after 3 days' incubation.

Growth in liquid medium. The maximum number of viable organisms of strain no. A40, expressed as CCU per ml, was $10^{9}$ in some batches of medium after $48 \mathrm{hr}$ of incubation, and the first colour change was usually seen at this time. Some other strains, e.g., no. Ha176, grew even more rapidly, maximum numbers of organisms being present after $24 \mathrm{hr}$. All strains after incubation for about $72 \mathrm{hr}$ produced films on the surface of media with turbidity and sediment. Sometimes, growth did not occur in liquid medium though colonies developed on the same medium solidified with agar. Growth was not detected in the absence of serum.

Antibiotic-free medium. After initial isolation of the strains colonies were picked and inoculated into medium without penicillin or thallium acetate. After three passages subcultures were made to solid media. Typical mycoplasma colonies, but no bacterial colonies, developed.

J. MED. MICROBIOL.-VOL. 5 (1972) 
Other features. All the strains were characterised by their ability to metabolise arginine but not glucose or urea. Growth of the strains was not inhibited by the addition of 0.001 per cent. methylene blue to liquid medium; nor was the dye decolorised. On several occasions colonies of the strains failed to haemolyse guinea-pig erythrocytes when these were layered over as a 3 per cent. suspension and the plates incubated at $37^{\circ} \mathrm{C}$ for $48 \mathrm{hr}$; nor did the guinea-pig erythrocytes adsorb to the colonies.

TABLE I

Serological relationships among the arginine-utilising porcine mycoplasmas, based on inhibition by antiserum to strain no. A40

\begin{tabular}{l|l|c|c}
\hline $\begin{array}{c}\text { Strain } \\
\text { no. }\end{array}$ & \multicolumn{1}{|c|}{ Isolated from } & $\begin{array}{c}\text { Zone (mm) of colony } \\
\text { inhibition on agar }\end{array}$ & $\begin{array}{c}\text { Metabolism-inhibition } \\
\text { titre }\end{array}$ \\
\hline A40 & lung* (active pneumonic lesions) & $6 \cdot 0$ & 4096 \\
A58 & lung* (pleurisy; old lesions) & $3 \cdot 5$ & 2560 \\
Ha176 & lung (no macroscopic lesions) & $7 \cdot 0$ & 1280 \\
Ha1 & nasal cavity & $3 \cdot 0$ & 5120 \\
Ha34 & lung (active pneumonic lesions) & $2 \cdot 5$ & 5120 \\
A26 & lung* (resolving lesions) & 2.0 & 320 \\
Ha8 & nasal cavity & $2 \cdot 0$ & 1280 \\
Ha32 & lung (active pneumonic lesions) & $1 \cdot 5$ & 320 \\
P45 & lung (pathology not known) & $6 \cdot 0$ & 2560 \\
S614 & joint & $4 \cdot 0$ & 2560 \\
\hline
\end{tabular}

* M. hyorhinis was also isolated from this lung.

\section{Serological studies}

Relationship between A-U mycoplasma strains. Eight A-U mycoplasma strains isolated by one of us (MG), an A-U strain (no. P45) isolated by Dr D. H. Roberts, Central Veterinary Laboratory, Weybridge, and strain no. S614 isolated by Dr J. Nicolet, University of Bern, Switzerland, were tested with antiserum to strain A40 by the GI and MI techniques (table I). Zones of colony inhibition of at least $1.5 \mathrm{~mm}$ were observed with all these strains. In the MI tests, the inhibition titres observed with strain A40 and the other strains were similar, except in the case of two of them; for these, the MI titres were about ten-fold lower. Notwithstanding this, the results indicated that all the strains were closely related.

Relationship of $A-U$ strains to other mycoplasmas. Antisera against the known arginine-metabolising mycoplasmas and antisera to some glucosefermenting mycoplasmas were tested against the A-U strain no. A40 by the GI and MI techniques (table II). Each antiserum inhibited colonial growth and metabolism of the homologous mycoplasma but not of strain no. A40. Further, A40 antiserum, apart from inhibiting the metabolism of $M$. hominis at low titre, failed to inhibit the metabolism and growth of the other mycoplasmas. These results showed that strain no. A40 and those closely related to it were serologically distinct from other known mycoplasmas. 
PORCINE MYCOPLASMAS

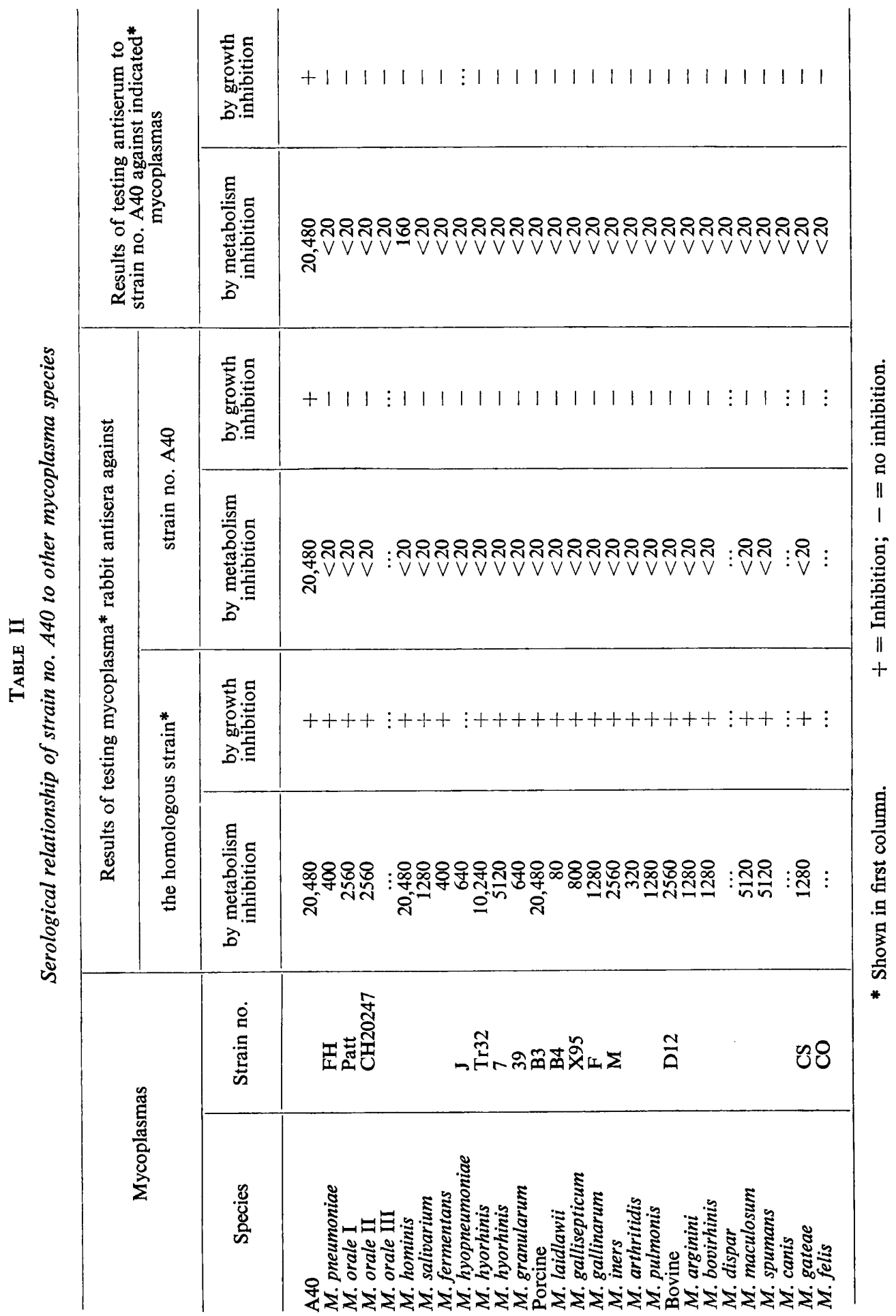


Relationship of $A-U$ strains to recently named porcine mycoplasmas. $M$. hyosynoviae (strain no. S16), isolated from the joints of pigs, was obtained from Dr R. F. Ross, Veterinary Medical Research Institute, Iowa State University, Ames, Iowa, USA. M. suidaniae (strain no. M60), isolated from lungs of pigs, was obtained from Dr N. F. Friis, State Veterinary Serum Laboratory, Copenhagen, Denmark.

In GI tests, antisera to strains S16 and M60 produced inhibition zones of $10 \mathrm{~mm}$ and $7.5 \mathrm{~mm}$, respectively, against their homologous organisms. The same antisera produced zones of $7.0 \mathrm{~mm}$ and $6.0 \mathrm{~mm}$, respectively, in GI tests against the A-U strain no. A40. Antiserum to the latter produced a zone of $10 \mathrm{~mm}$ when tested against the homologous mycoplasma, and zones of $6.0 \mathrm{~mm}$ and $8.0 \mathrm{~mm}$ in tests with strain no. M60 and strain no. S16 respectively.

In MI tests, antiserum to strain S16 inhibited at a dilution of 1 in 10,240 the metabolism of its homologous organism as well as that of strain no. A40. Similarly, antiserum to the latter strain inhibited its metabolism at a dilution of 1 in 10,240 and inhibited that of strain S16 at a dilution of 1 in 5120. These results clearly indicated the very close serological relationship between strain no. A40 and strains no. S16 and M60.

\section{DISCUSSION}

The arginine-utilising strains described have been isolated from a number of pigs and in different localities so it seems improbable that they are chance contaminants in these animals. The very frequent occurrence of $M$. hyorhinis in the pig respiratory tract may obscure the presence of the A-U strains. If subcultures of primary isolation cultures were made within the first 4 days of incubation $M$. hyorhinis was isolated. However, subcultures after 4-5 days or more of incubation yielded A-U strains only. The more rapid death of $M$. hyorhinis is in accord with the observation of Switzer (1969) that recent isolates of this mycoplasma were frequently not viable by the 4th day of incubation. Although several of the A-U strains were isolated from diseased lungs there is no evidence that they are capable of causing disease. Some preliminary observations on inoculated gnotobiotic pigs suggest that the strains are not pathogenic in the respiratory tract.

The nature of the colonies, the failure to observe bacterial colony formation after passage in antibiotic-free medium and various other biological features leave us in no doubt that the organisms studied are mycoplasmas. Serologically all these A-U strains were related to one another, though they are possibly not identical. Thus, antiserum to one of the strains (no. A40) was at least ten-fold less effective in inhibiting the metabolism of strains no. A26 and no. Ha32 than it was in inhibiting the homologous strain. Differences of this sort within a group of closely related mycoplasma strains have been observed previously with $M$. gallisepticum (Taylor-Robinson and Berry, 1969), M. hominis (Hollingdale and Lemcke, 1970) and other mycoplasma species. In attempts to define whether the A-U strains were distinct from other known mycoplasma species we examined, as recommended by the subcommittee on the nomenclature of Mycoplasmatales (Edward et al., 1967), their serological relationship 
to known species. These included the acknowledged mycoplasma species previously isolated from pigs, all other A-U mycoplasmas, and a number of glucose-metabolising mycoplasmas that were readily available. We did not consider it necessary to examine the serological relationship to all glucosefermenting strains, nor to any of the T-mycoplasmas which, on the basis of their unique metabolic and other characteristics, are clearly distinct. It seemed desirable to consider the relationship of the A-U strains with $M$. hyogenitalium and $M$. hyoarthrinosa (Moore, Redmond and Livingstone, 1965) particularly as the latter was said to alkalinise the medium. However, the status of these organisms as mycoplasmas is in doubt (Edward and Freundt, 1969) and unfortunately we have not been able to propagate $M$. hyoarthrinosa. Because our studies indicated that the A-U strains were different from the acknowledged porcine species and indeed from other species that we examined, we thought that they comprised a new species and we tentatively proposed the name $M$. hyoarginini (Goiš and Taylor-Robinson, 1970). However, this term is not acceptable since, after completion of the main body of work, we discovered that the arginine-metabolising mycoplasmas designated $M$. hyosynoviae and $M$. suidaniae were closely similar to those we had studied. Of the various terms, $M$. hyosynoviae seems to have priority. We have deposited strain no. A40 in the National Collection of Type Cultures (Colindale) under NCTC10140.

\section{SUMMARY}

The biological characteristics of eight mycoplasma strains isolated from the nasal cavities or lungs of pigs, and two strains obtained from pigs by other workers, were examined. All strains metabolised arginine but not glucose or urea. They produced characteristic " fried-egg" colonies, but did not grow in medium without serum. Bacterial colonies were not observed after passage of the strains in medium without antibiotics. The colonies did not cause rapid haemolysis of guinea-pig erythrocytes, nor did these cells adhere to the colonies. On the basis of metabolism-inhibition and disk growth-inhibition tests, the strains were closely related to one another. They were different from other mycoplasmas previously isolated from pigs, from various other animal mycoplasmas, and from all other known arginine-utilising mycoplasmas except the recently named $M$. hyosynoviae and $M$. suidaniae. It seems that the strains comprise a new mycoplasma species, are present in pigs in various parts of the world, and that the generic name $M$. hyosynoviae has priority.

In addition to those mentioned in the text, we thank the following for mycoplasma strains or antisera: Drs B. E. Andrews (Mycoplasma Reference Lab., Colindale, London), D. G. ff. Edward (PHLS, County Hall, London), R. Hodges and G. Jackson (Royal Veterinary College, London), R. N. Gourlay (Institute for Research on Animal Diseases, Compton), W. P. Switzer (Veterinary Medical Research Inst., Iowa), B. C. Cole (University of Utah) and Z. Dinter (Wallenberg Lab., Uppsala, Sweden). We also thank Dr R. H. Purcell (National Institutes of Health, Bethesda, USA) for testing antiserum to strain no. A40 against $M$. orale III. M. G. acknowledges a personal grant from the Meat and Livestock Commission, which substantially supported this investigation. 


\section{REFERENCES}

CLYDE, W. A., JR 1964. Mycoplasma species identification based upon growth inhibition by specific antisera. J. Immun., $92,958$.

Dinter, Z., Danielsson, D., AND BaKos, K. 1965. Differentiation of porcine mycoplasma strains. J. Gen. Microbiol., 41, 77.

Edward, D. G. FF., AND Freundt, E. A. 1969. Classification of the Mycoplasmatales. In The Mycoplasmatales and the L-phase of bacteria, ed. by L. Hayflick, New York, p. 147.

Edward, D. G. FF., Freundt, E. A., Chanock, R. M., Fabricant, J., Hayflick, L., LemCKe, Ruth M., Razin, S., Somerson, N. L., AND Wittler, Ruth G. 1967. Recommendations on nomenclature of the Order Mycoplasmatales. Science, N.Y., 155, 1694.

FrIIs, N. F. 1970. A new porcine mycoplasma species: Mycoplasma suidaniae. Acta vet. scand., 11, 487.

GoIš, M., AND TAYLOR-RoBINSON, D. 1970. The identification and characterization of some porcine arginine-utilizing mycoplasma strains. Abstr. X Conf. on taxonomy of bacteria and mycoplasmas, Brno, Czechoslovakia.

Goodwin, R. F. W., Pomeroy, Annette P., and Whittlestone, P. 1965. Production of enzootic pneumonia in pigs with a mycoplasma. Vet. Rec., 77, 1247.

Goodwin, R. F. W., Pomeroy, AnNette P., ANd Whittlestone, P. 1967. Characterization of Mycoplasma suipneumoniae: a mycoplasma causing enzootic pneumonia of pigs. J. Hyg., Camb., 65, 85.

HERDERSCHEÊ, D. 1963. An improved medium for the cultivation of the Eaton agent. Antonie van Leeuwenhoek, 29, 154.

Hollingdale, M. R., AND LemCKe, Ruth M. 1970. Antigenic differences within the species Mycoplasma hominis. J. Hyg., Camb., 68, 469.

MOORE, R. W., Redmond, H. E., AND Livingstone, C. W. 1965. Mycoplasmosis (PPLO) of swine. SWest. Vet., 19, 19.

Purcell, R. H., Taylor-Robinson, D., Wong, D. C., ANd Chanock, R. M. 1966. A color test for the measurement of antibody to the non-acid-forming human mycoplasma species. Amer. J. Epidemiol., 84, 51.

RoBERTS, D. H., AND Golš, M. 1970. A previously unreported serotype of porcine mycoplasma. Vet. Rec., 87, 214.

Ross, R. F., AND KARMON, JudITH A. 1970. Heterogeneity among strains of Mycoplasma granularum and identification of Mycoplasma hyosynoviae, sp. n. J. Bact., 103, 707.

Swrtzer, W. P. 1964. Mycoplasmosis. In Diseases of swine, 2nd ed., edited by H. W. Dunne, Ames, Iowa, p. 498.

SwITZER, W. P. 1969. Swine mycoplasmas. In The Mycoplasmatales and the L-phase of bacteria, ed. by L. Hayflick, New York, p. 607.

TAYLOR-ROBINSON, D., AND BERRY, D. M. 1969. The evaluation of the metabolic-inhibition technique for the study of Mycoplasma gallisepticum. J. Gen. Microbiol., 55, 127.

TAYLOR-ROBINSON, D., AND DINTER, Z. 1968. Unexpected serotypes of mycoplasmas isolated from pigs. J. Gen. Microbiol., 53, 221.

Taylor-Robinson, D., Purcell, R. H., Wong, D. C., and Chanock, R. M. 1966. A colour test for the measurement of antibody to certain mycoplasma species based upon the inhibition of acid production. J. Hyg., Camb., 64, 91. 